\title{
Who Would You Like to Work With?
}

\section{Use of Individual Characteristics and Social Networks in Team Formation Systems}

\author{
Diego Gómez-Zará ${ }^{\dagger}$ \\ P. Universidad Católica de Chile \\ Facultad de Comunicaciones \\ dgomezara@uc.cl \\ Jacqueline N. Lane \\ Harvard Business School \\ Laboratory of Innovation Science \\ jng@hbs.edu
}

\author{
Matthew Paras \\ Northwestern University \\ McCormick School of Engineering \\ mparas@u.northwestern.edu \\ Leslie A. DeChurch \\ Northwestern University \\ Communication Studies \\ dechurch@northwestern.edu
}

\author{
Marlon Twyman \\ Northwestern University \\ Technology and Social Behavior \\ marlont2@u.northwestern.edu \\ Noshir S. Contractor \\ Northwestern University \\ McCormick School of Engineering \\ nosh@northwestern.edu
}

\begin{abstract}
People and organizations are increasingly using online platforms to assemble teams. In response, HCI researchers have theorized frameworks and created systems to support team assembly. However, little is known about how users search for and choose teammates on these platforms. We conducted a field study where 530 participants used a team formation system to assemble project teams. We describe how users' traits and social networks influence their teammate searches, teammate choices, and team composition. Our results show that (a) what users initially search for differs from what they finally choose: initially they search for experts and sociable users, but they are ultimately more likely to choose their prior social connections; (b) users' decisions lead to nondiverse and segregated teams, where most of the expertise and social capital are concentrated in a few teams. We discuss the implications of these results for designing team formation systems than promote users' agency.
\end{abstract}

\section{CCS CONCEPTS}

- Human-centered computing $\rightarrow$ Collaborative and social computing theory, concepts and paradigms; Empirical studies in HCI.

\footnotetext{
${ }^{*}$ Corresponding author.

${ }^{\dagger}$ Also with Northwestern University, Technology and Social Behavior.
}

Permission to make digital or hard copies of all or part of this work for personal or classroom use is granted without fee provided that copies are not made or distributed for profit or commercial advantage and that copies bear this notice and the full citation on the first page. Copyrights for components of this work owned by others than the author(s) must be honored. Abstracting with credit is permitted. To copy otherwise, or republish, to post on servers or to redistribute to lists, requires prior specific permission and/or a fee. Request permissions from permissions@acm.org. CHI 2019, May 4-9, 2019, Glasgow, Scotland Uk

(c) 2019 Copyright held by the owner/author(s). Publication rights licensed to ACM.

ACM ISBN 978-1-4503-5970-2/19/05 .. \$15.00

https://doi.org/10.1145/3290605.3300889

\section{KEYWORDS}

Teams, team formation systems, people search, human capital, social capital.

\section{ACM Reference Format:}

Diego Gómez-Zará, Matthew Paras, Marlon Twyman, Jacqueline N. Lane, Leslie A. DeChurch, and Noshir S. Contractor. 2019. Who Would You Like to Work With?: Use of Individual Characteristics and Social Networks in Team Formation Systems. In CHI Conference on Human Factors in Computing Systems Proceedings (CHI 2019), May 4-9, 2019, Glasgow, Scotland Uk. ACM, New York, NY, USA, 15 pages. https://doi.org/10.1145/3290605.3300889

\section{INTRODUCTION}

Team formation processes are relocating into online spaces as people and organizations look for collaborators and assemble teams through enterprise and social media platforms $[5,61]$. Teams assembled online are increasing in many collaborative work environments: crowdsourcing [65], research projects [77], MOOCs [73], virtual spaces [32, 81], educational settings [2], startups [12], hackathons [76], software companies [38, 43], and other organizational contexts [46]. Since online platforms have the potential to reconfigure team formation, designers of collaborative systems are increasingly developing team formation frameworks for tailoring users interactions $[50,68,81]$, incorporating recommender systems $[4,15]$, and augmenting users actions in online environments [65, 87].

Despite the expanding interest in online team assembly, little attention has been paid to users' behaviors when searching and choosing teammates. How members use these systems have direct consequences for the formation of their teams. Previous studies have acknowledged that ad hoc team formation processes lead to disharmony among members, lack of cohesion, organization, and diversity [9, 51, 53]. For example, unbalanced skills among team members is the third most significant contributing factor to startup failures in the U.S. [18]. Understanding how users search for and choose 
teammates via online platforms can lead to rethinking technological features that enhance the assembly of teams.

In this study, we explore how users exercise their agency when looking for and choosing teammates during online team formation. We conducted a field study with 530 students who assembled 91 project teams using an online team formation system. By analyzing digital trace and survey data, we measured how users' human and social capital affected users' searches, choices, and final decisions on team formation. Additionally, we studied how users' decisions affected the distribution of human capital and social capital in resulting teams.

We found that while searching for teammates, users used the system to look for competent and social individuals. However, users ultimately relied on their prior social networks to select and accept their teammates (e.g., previous collaborators or popular individuals). We also found that teams segregated into clusters of expertise (i.e., most of the experts formed teams together), and similarly, into clusters of social connections (i.e., popular users formed teams together). Our results suggest that team formation systems that enable users' agency can lead to a high preference for teaming-up with prior social connections and also enhance disparities among teams, with some teams having the best talent and leaving other teams disadvantaged. We discuss how these results illuminate the design of future team formation systems that enable users to exercise their agency and assemble their teams.

This paper contributes to the literature by providing (1) a theoretical conceptualization of how people search for and choose teammates using online team formation systems, (2) a quantitative analysis articulating users' searches, choices, and their final team composition, and (3) a discussion of the design implications of team formation systems to promote both team diversity and user agency.

\section{RELATED WORK AND BACKGROUND}

We situate our work in the context of prior studies of team formation systems, team composition, and teammate selection across the HCI and organizational behavior literature.

\subsection{Team formation systems}

Previous studies have made efforts to understand team formation strategies in online systems. Several tools have been developed to support users' collaborative efforts for establishing groups, placing an emphasis on increasing teams' diversity $[55,66]$, cohesion $[31,60]$, and performance $[44,58,69]$. Online systems use different strategies based on the extent to which users can exercise their agency in teammate selection: from having full freedom to choose teammates, to having team structures designed by algorithms. Recent studies using computational augmentation include flash teams systems -which allow the assembly of teams of experts by modularizing a project's tasks and assigning online workers to them [65]- and a system that identifies and reconfigures group structures for existing teams based on their current performance and members' experience [87].

Other team formation systems enable users to assemble their own teams by searching for teammates [39, 45]. In the study of one system, instructors selected specific criteria for teammate searching in a project-based course [42]. Students appreciated the use of rational criteria when assembling their own teams, arguing that the system reduced their stress and simplified the team formation process. However, other students disliked the search criteria selected by the instructors. Other example systems are based on filling defined team roles (e.g., sales teams [3]) and supporting "team dating" in online platforms [50], whereby users have short consecutive "dates" with other users to evaluate potential teammates. The relevance of previous connections is apparent by users' preference to choose those who they had previously "dated."

While related research has explored multiple strategies employed by team formation systems, much less is known about how users make decisions in each stage of team formation, as well as the impact of these individual decisions on the final composition of the team. Our study addresses this gap by examining users' behaviors, searches, choices, and ultimately, the final team compositions.

\subsection{Team composition}

Team assembly affects team effectiveness in terms of performance [82], functional diversity [20, 78], cohesion [16, 67], innovation [62], access to ideas and resources [14], as well as individual outcomes [53]. Although team success is ultimately contingent, research and practice suggest that team composition sets the stage for effective team outcomes and processes [52]. We explore important factors in the research on team composition that are affected by users' decisions on their teammates.

2.2.1 Performance. Team composition leads to success or failure. Prior work has identified many determinants of success after members have assembled teams [82]. Research has empirically demonstrated that team composition influences team performance. For example, gender composition, personality, teamwork knowledge, value and belief, and cognitive ability are a few among many attributes that have been linked to team process and performance [23]. However, the factors that promote performance after the team has been formed are not necessarily generalizable to those that explain what happens at the team assembly stage [35].

2.2.2 Functional diversity. Teams' functional diversity is a consequence of members' choices. It is the degree to which 
team members differ in terms of their experience or backgrounds [11, 20]. Functional diversity can facilitate atypical combination of knowledge that prompt novelty and breakthroughs [77]. In one study [78], software development teams' productivity was improved by increasing gender and tenure diversity. Despite the benefits of functional diversity, research has found that team members struggle when searching, bridging, codifying, and integrating ideas from unfamiliar domains [6]. This may lead individuals to avoid forming teams with diverse and/or unfamiliar individuals. As a consequence, the balance between similarity and diversity in teams would depend on what people look for when choosing collaborators and assembling teams [37].

2.2.3 Team cohesion. The tendency for a team to stick together and remain united in the pursuit of its instrumental objectives and/or for the satisfaction of members' affective needs is known as team cohesion [16]. The selection of certain kinds of collaborators affects team cohesion, which can be driven by looking for the most competent individuals for specific work (i.e., task-cohesion) or for those enjoyable to work with in general (i.e., social-cohesion) [67]. In this pursuit of cohesion, team members may both look for others who are inter-personally similar to them and for people with shared views and commitment to the team tasks [84] Users' choices could however lead to less cohesive teams: for example, if they seek out the most competent individuals, this can create a team that lacks the relational ties that are needed to engage in effective teamwork [17].

2.2.4 Connectivity. Teams' connectivity or access to ideas that reside across teams is another consequence of how people look for potential collaborators. Teammates rely on shared members or team interlocks [49] to gain access to ideas, constraints, and opportunities that lie beyond their boundaries $[22,57,72]$. Teams which are well connected internally and externally are more innovative and outperform their less connected counterparts [62]. As a result, people may look to team up with influential members who have more access to resources via their connections [14].

\subsection{Teammate selection: human and social capital}

During team formation, users can select teammates based on specific attributes, such as similarity, familiarity, or competence [37]. Online platforms enable people to search for others across multiple purposes: looking for friendship [19, $21,64]$, communities [47, 86], work collaboration [36, 85], and romantic dates [88, 89]. Users can search for others by their names or desired qualities (e.g., skills, locations, etc.) [80].

Desirable attributes for teammates can be classified as either elements of human capital or social capital [40]. Human capital refers to the knowledge, skills, abilities, and/or experiences of individuals [8]. Social capital refers to individuals' social relationships with others [48]. Based on these two types of capital, we disaggregate four elements that can explain the search and choice of teammates: from human capital, competence and warmth, and from social capital, bonding capital and bridging capital [83].

2.3.1 Competence. Competence-or expertise-refers to traits related to perceived ability (e.g., intelligence, skill, and efficacy) [29], and describes a person's knowledge about a certain domain, process, or technology [7]. Competent users with relevant skills are "attractive" to work with on a project.

2.3.2 Warmth. Warmth captures traits that are related to perceived intent (e.g., friendliness, helpfulness, sincerity, trustworthiness, and morality) [29]. A person's warmth portends trustworthiness and allows a degree of predictability in a relationship.

2.3.3 Bonding capital. Bonding social capital characterizes the quality of a connection between two people. People choose close friends (strong ties) or strangers (weak ties) for different purposes. Working with prior collaborators increases the certainty of working styles, communication, and outcomes [37]. Working with weak ties increases access to novel information [33].

2.3.4 Bridging capital. Bridging social capital is characterized by occupying an advantaged position in social networks (e.g., a high popularity, brokerage, or closeness value) [13]. People who are brokers fill the structural holes between disconnected individuals, allowing more access and control over information and resources [30, 54].

Taken together, these human and social capital dimensions provide a useful conceptual lens through which to understand the characteristics that relevant for choosing collaborators and give insight into the differences that matter most in a collaborator.

\subsection{Research questions}

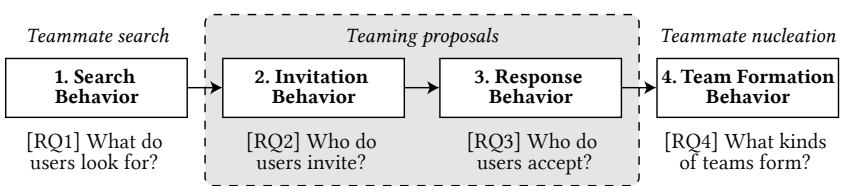

Figure 1: Team formation stages and research questions

The studies reviewed above provide a conceptual lens to understand the characteristics that are important in team formation processes when users have agency on choosing their teammates [24]. Based on these characteristics, we delineate the social cognitive processes involved in searching for and 


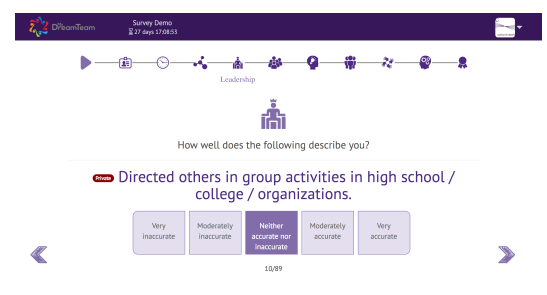

(a) Initial survey stage: users complete their profile, individual traits, and social network information

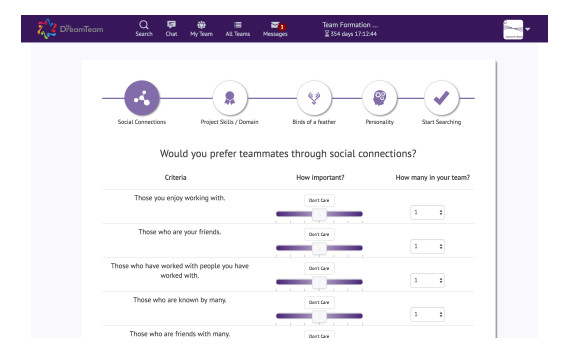

(b) Users search for collaborators using competence, warmth, bonding, and bridging capital attributes

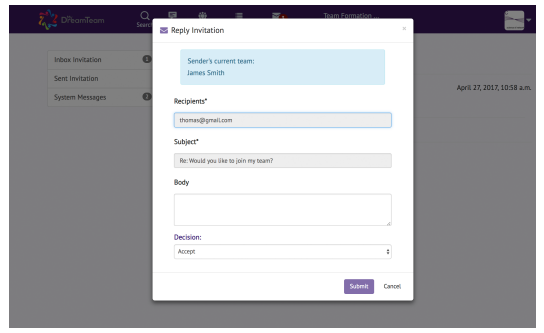

(c) Invitation stage: users receive an invitation for team membership. They can accept, decline, or ignore it.

Figure 2: Interfaces of team formation system used in this study

choosing teammates via online platforms in four stages that correspond to our research questions (Figure 1).

In the first stage, we aim to understand what people seek out from others [RQ1]. In the second stage, we aim to analyze which individuals are more likely to receive an invitation [RQ2]. Then, in the third stage, we aim to understand the fundamental factors for accepting or declining an invitation [RQ3]. Finally, we assess the composition of teams at the end of the entire process [RQ4].

\section{METHOD}

Based on our research questions, we designed a field study to observe team assembly in an online setting. To facilitate our study, we developed an online team formation system where users assemble teams by searching, inviting, and accepting (or declining) invitations from others. We analyzed all four team formation stages based on the human and social capital dimensions explored. The first three stages use behavioral data generated during team assembly from an online team formation system and the fourth stage is analyzed using behavioral data as well their responses to a survey.

\subsection{Participants}

In total, 530 individuals participated across 9 independent case studies at universities in the United States between 2016 and 2018. Students organized into 91 teams in order to complete a required course project. We conducted our study in five undergraduate courses taught by several professors in three universities. 314 undergraduate students participated and their nationality breakdown is as follows: 61\% were Americans, 32\% were international, and 7\% did not report. As part of undergraduate students' assignments, they assembled teams to complete a course project. Similarly, 216 graduate students at one university in the United States participated in this study, spread across four graduate courses. Regarding their nationalities, 60\% were Americans, $34 \%$ were international, and $6 \%$ did not report it. Graduate students self-assembled into teams to analyze case studies and participate in discussion groups.

In each case study, all students were asked to self-organize into teams for their term project. Students did not participate in more than one class and worked on more than one team either. The topics of these projects ranged from consulting teams to app development. The sample includes an equal distribution of males and females, and average age ranged from 20 to 31 years. Participation in this study and the use of the team formation system was voluntary and consented. They could withdraw their consent at any time during the case study. The research team provided manuals, help elements, and a video tutorial to explain the overall process of the research to all students. We explained to the students that the use of this system will not affect their grades for the course.

\subsection{Initial survey}

The first task for participants was completing a public user profile. They identified themselves using their real names and completed profiles by replying to a set of open-ended questions about their backgrounds, skills, favorite things to do, and motivation to take the course. This information was available for other participants to view.

Next, as part of registration in the team formation system, participants completed a survey assessing human and social capital. This survey included questions relating to their demographic information, creativity, leadership experience, psychological collectivism, social skills, personality, project skills, and relationships to others in the network (Figure 2a). This information was used to provide results in response to users' searches. Participants were allowed up to two weeks to complete this survey. After all participants completed the survey, they were able to search for and invite users to their team.

3.2.1 Demographic information. As control variables, we asked participants their gender, age, and nationality. We also 
controlled whether they were undergraduate or graduate students.

3.2.2 Competence. To assess this human capital dimension, participants answered six items regarding their expertise on skills relevant to the team project. These items were adapted for each project, often considered a set of computational, statistical, communication, and research skills. The main distinction was determined by the type of course (undergraduate or graduate). While the former used the same set of skills (3 technical expertise skills and 3 communication skills), the latter used specific skills related to the course's project. These items were assessed on a 5-point Likert scale [63], which ranged from "Not at all skilled" to "Extremely skilled."

3.2.3 Warmth. We defined creativity, leadership experience, psychological collectivism, social skills, and personality as part of warmth skills:

Creativity. Creativity is a dimension of warmth because a creative mindset relates to a person's self-efficacy and ability to have positive and affective relationships [75]. We asked participants about their ability to produce creative outcomes and be creative in their work roles. We used [75]'s three-item scale to measure this trait. For each participant, we averaged these three items in one score $(\alpha=.86)$.

Leadership experience. We used the Adolescent Leadership Activities Scale [56] with slight modifications to reflect that participants could have participated in leadership in both high school and college. Participants answered eight items relating to previous leadership behaviors on a 5-point Likert scale of how well each statement described them ranging from "very inaccurate" to "very accurate." For each participant, we averaged these eight items in one score $(\alpha=.83)$.

Psychological collectivism. To assess the extent to which participants valued teamwork and team's success, we used each of the five facets of psychological collectivism in the form of 15 questions in this study [41]. These questions were assessed on a 5-point Likert scale, which ranged from "strongly disagree" to "strongly agree." We averaged the fifteen items in one score per participant $(\alpha=.89)$.

Social skills. We used the Political Skill Inventory [28] to target four key dimensions of desired political behaviors: social astuteness, interpersonal influence, networking ability, and apparent sincerity. Participants answered seven items, which corresponded to each of the four facets. We assessed these items on a 7-point Likert scale, which ranged from "strongly disagree" to "strongly agree." These items were also averaged per participant $(\alpha=.85)$.

Personality. The mini-International Personality Item Pool (IPIP) scales were used to assess all Big Five personality traits [26]. Participants responded to 20 items on a 5-point Likert scale about how well each statement describes them ranging from "very inaccurate" to "very accurate." For each user, we averaged the four questions for each of the five traits: agreeableness, conscientiousness, extraversion, neuroticism, and openness $(\alpha=.79)$.

3.2.4 Bonding capital. Participants were asked three questions: "Who on this list do you know?", "Who have you worked with on projects?", "With whom on this list do you enjoy working?". Based on their answers, we created three different directed networks: Contact network, Collaboration network, and Friendship network, corresponding to each question respectively. If they nominated another person for any of the questions, a relation was formed in the corresponding network.

3.2.5 Bridging capital. Based on the previous three social networks, we operationalized four network metrics for each user to calculate their bridging capital [79]:

Popularity: Users' indegree as the sum of how many people mentioned them as a contact / collaborator / friend.

Activity: Users' outdegree as the sum of how many they nominated another as a contact / collaborator / friend.

Betweenness: User's brokerage as the number of shortest paths between participants that pass through the user.

Closeness: The inverse of the sum of the length of the shortest paths between that user and all other participants.

\subsection{Search for teammates}

Once all participants completed the survey, they were able to search for and select teammates. Users searched for teammates using queries (Figure $2 \mathrm{~b}$ ). A query in the system is a set of search preferences explicitly made by a user, representing considerations for potential teammates based on human and social capital. In each query, users had to select at least two criteria and rate the importance of these criteria using a 7-point scale, ranging from "Not important at all" $(-3)$ to "Yes, for sure!" (+3), including "Don't care" (0). By default, all the criteria were set in 0 and the user had to manually change the criteria's importance to create a query.

The system computed a score for each potential teammate $j$ matching searcher $i$ 's queries according to the following formula: $S_{i j}=\sum_{k \in K} \alpha_{k} s_{i j k}$, where $\alpha_{k}$ is the importance of the criteria $k$ in the query. Then, each score of $s_{i j k}$ considers the potential teammate $j$ 's score of the criterion $k$ in relation to the searcher $i$. The formulas for each $s_{i j k}$ are listed in Table 1. Finally, the system used the $S_{i j}$ scores to display a rank-ordered list of the potential teammates that best fit the user $i$ 's query. The system paginated all the results ordered according to the user's query- in pages with ten profiles. For each potential teammate, the system displayed their picture, the percentage of how well their matched with the user's query, a link to their full public profile (containing 
the responses to open-ended questions described above), and an invite button.

Users also had the option to directly specify others' names in order to see their profiles directly and potentially send an invitation. Here again, the system provided a picture of each potential teammate, a brief description, a button that links to their full public profile, and an invite button.

Table 1: Search preferences available on the system

\begin{tabular}{|c|c|c|}
\hline Attribute & Label displayed & Formula \\
\hline \multicolumn{3}{|l|}{ Competence } \\
\hline Project Skill \#1 & Project Skill \#1 & User j's project skill \#1 score \\
\hline Project Skill \#2 & Project Skill \#2 & User j's project skill \#2 score \\
\hline Project Skill \#3 & Project Skill \#3 & User $j$ 's project skill \#3 score \\
\hline Project Skill \#4 & Project Skill \#4 & User $j$ 's project skill \#4 score \\
\hline Project Skill \#5 & Project Skill \#5 & User $j$ 's project skill \#5 score \\
\hline Project Skill \#6 & Project Skill \#6 & User $j$ 's project skill \#6 score \\
\hline \multicolumn{3}{|l|}{ Warmth } \\
\hline $\begin{array}{l}\text { Psychological } \\
\text { collectivism }\end{array}$ & $\begin{array}{l}\text { Those who have strong team } \\
\text { values }\end{array}$ & $\begin{array}{l}\text { User } j \text { 's p. collectivism overall } \\
\text { score }\end{array}$ \\
\hline Creativity & Those with a creative mind & User $j$ 's creativity overall score \\
\hline Social skills & $\begin{array}{l}\text { Those who have good social } \\
\text { skills }\end{array}$ & $\begin{array}{l}\text { User } j \text { 's social skills overall } \\
\text { score }\end{array}$ \\
\hline Leadership experience & $\begin{array}{l}\text { Those with good leadership } \\
\text { experience }\end{array}$ & $\begin{array}{l}\text { User } j \text { 's leadership experience } \\
\text { overall score }\end{array}$ \\
\hline Similar personality & $\begin{array}{l}\text { Those who have a similar } \\
\text { personality to you }\end{array}$ & $\begin{array}{l}\text { Cosine similarity between users } \\
\text { across personality features }\end{array}$ \\
\hline \multicolumn{3}{|l|}{ Bonding capital } \\
\hline Worked within the past & $\begin{array}{l}\text { Those you have worked within } \\
\text { the past }\end{array}$ & $\begin{array}{l}\text { User } i \text { mentioned user } j \text { as a } \\
\text { co-worker }\end{array}$ \\
\hline Friendship & Those who are your friends & $\begin{array}{l}\text { User } i \text { mentioned user } j \text { as a } \\
\text { friend }\end{array}$ \\
\hline Shared collaborators & $\begin{array}{l}\text { Those who have worked with } \\
\text { people you have worked with }\end{array}$ & $\begin{array}{l}\text { If user } i \text { have worked with user } \\
j \text {, and user } k \text { with user } j \text {, then } \\
\text { user } k \text { is displayed. }\end{array}$ \\
\hline \multicolumn{3}{|l|}{ Bridging capital } \\
\hline Social network brokers & $\begin{array}{l}\text { Those who can introduce you to } \\
\text { many }\end{array}$ & Users' betweenness \\
\hline Work popularity & $\begin{array}{l}\text { Those who have worked with } \\
\text { many }\end{array}$ & Users' indegree \\
\hline Know popularity & Those who are known by many & Users' indegree \\
\hline Friend popularity & $\begin{array}{l}\text { Those who are friends with } \\
\text { many }\end{array}$ & Users' indegree \\
\hline
\end{tabular}

\subsection{Team Assembly}

Users sent invitations asking other users to join their teams. When a user sent an invitation, a pre-populated message popup opened, and the user could either use the default message or add personalized text to the invitation (Figure 2c). Each invitation message also contained the sender's profile. The receiver of the invitation had the choice to accept, decline, or ignore the invitation. If a user not on a team accepts an invitation from another user not in a team, the system creates a new team with them. If two users who are on two existing teams accept to work together, both pre-existing teams will merge and establish a unique team only if and only the final team size is less than or equal to the maximum team size allowed. The system does not designate a leader of the team; as a result, any person on the team has the ability to invite new members or merge teams, and any member on another team who has been invited may choose to accept the invite and merge the teams. Users also had the option to leave a team. The system offered them an option to share with their former teammates their motives for leaving the team. Once a team was finalized, they were not be able to accept any new members. When the team assembly deadline was reached, students started working on their respective course projects over a 10-week period. If some students were unable to assemble into a team by the deadline, the class' instructor assigned them to a team using the system. Overall, team sizes ranged from 4 to 6 members $(M=5.13, S D=.93)$.

\subsection{Analytic approach}

We conducted separate descriptive analyses and statistical models to explain participants' searches, invitations, acceptances, and the final teams compositions. To examine RQ1 -What do individuals look for?- we analyzed the number of search preferences used in each query to see whether users had a strong preference for competence, warmth, bonding capital, and bridging capital.

To respond to RQ2 -Who do individuals invite based on their current team formation stage?- we analyzed the likelihood of an invitation from one to another user. Similarly, to respond to RQ3 -Who do individuals accept based on their current team formation stage?- we analyzed the likelihood of accepting a user's invitation. We first operationalized the "team formation stages" according to the current state of users' teams (i.e., the number of users in the team at any given point) since the nine case studies had different spans of team formation, and participants' behavior changed over time as team size changed [70, 71]. To define these team formation stages, we checked the flow of invitations between users according to their teams' size. Teams' size was computed at the time that one of their members accepted or declined an invitation, which might have been different from when the invitation was extended. Figure 3a indicates the percentage of total invitations sent based on the number of individuals in the sending team and receiving team. Based on this analysis, we defined three invitational stages:

(i) Initiating a team $(60.8 \%$ of the total number of invitations) were invitations sent between users who were not yet on a team.

(ii) Growing a team (27.6\%) were invitations sent from users who are either not yet on a team or on a small team of 2-3 people, to recipients on any size team, excluding invites found in the first group.

(iii) Finalizing a team (11.6\%) were invitations from users who are on a large team of 4,5, or 6 people sent to users of any team size, looking to fill the remainder of their group.

We repeated this grouping method in order to also analyze acceptance and decline behavior, however now we considered the number of teammates at the moment of acceptance 


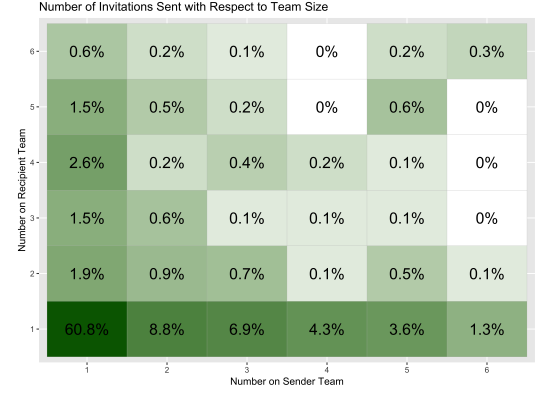

(a) Number of invitations sent with respect to team size (1,066 in total)

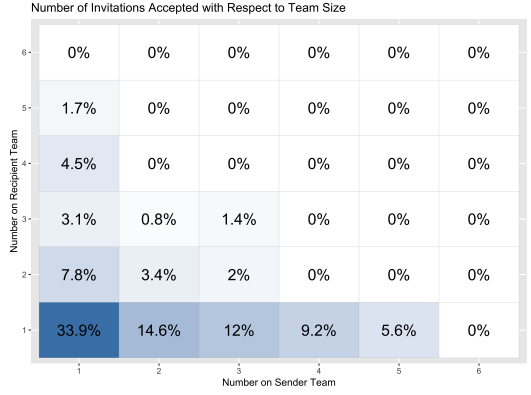

(b) Number of invitations accepted with respect to team size (357 in total)

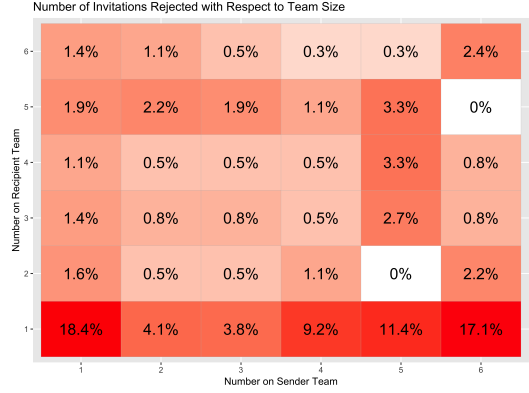

(c) Number of invitations declined with respect to team size (369 in total)

Figure 3: Distribution of invitations sent and responded

(Figure 3b) and decline (Figure 3c). These responses are then grouped into three-team formation stages:

(i) Initiating a team contains $(26.0 \%$ of the total responded invitations) only invitations accepted and declined between users who are not yet on a team.

(ii) Growing a team (59.2\%) contains invitations accepted and declined from users who on any size team, to recipients on a small team of 2-3 people.

(iii) Finalizing a team (14.8\%) contains invitations from users on any size that were accepted and declined by users who are on a large team of 4, 5, or 6 people.

Once we defined the team formation stages, we employed Hierarchical Logistic Models to explain users' decisions and account for the differences between the nine case studies [10]. HLM is an advanced form of logistic regression that allows us to examine the effects of independent variables (i.e., individual traits, social networks, and dyad relationships) on dependent variables (i.e., likelihood of receiving an invitation and accepting an invitation), considering potential correlations across the case studies (level-1) and the team formation stage (level-2). To calculate these HLMs, we use Generalized Linear Mixed Effects Models (GLM) using the binomial family (which, we coded 1 when an invitation was sent/accepted, otherwise, as 0 ). We normalized all numerical coefficients and verified that the calculated models meet the assumptions of linear regressions and have no overdispersion.

Finally, to respond RQ4 -What kinds of teams form?- we computed the distribution of participants' skills and network centrality measures of team members using $k$-means [74], which partitions the teams' users skills and degrees into $k$ clusters. The method calculates the mean squared value of each team and classifies it according to the nearest cluster's center. This analysis was done for 3, 4 and 5 clusters. We validated the consistency within clusters -their cohesion and separation- by calculating the Sum of Squared Error (SSE) of each cluster and the average silhouette coefficient over all teams' data. Three clusters was determined to be the best number of clusters for human capital (SSE=70, S.C. $=0.24)$ and social capital (SSE=201, S.C. $=0.42$ ), which captures appropriately the segmentation of these teams and were theoretically better supported.

\section{RESULTS}

\subsection{Users' initial survey}

Across the nine case studies ( $\mathrm{N}=530$ users), users had an average of $8.74(\mathrm{SD}=6.64)$ contacts, $4.81(\mathrm{SD}=4.36)$ collaborators, and $5.62(\mathrm{SD}=5.38)$ friends. These social networks were skewed: while $50 \%$ of the users were mentioned by less than 6 others as a contact, only $10 \%$ of them were mentioned by more than 25 users. These numbers are even more dispersed on the collaboration network and in the friendship network: in both cases, $50 \%$ of the people were mentioned by less than 4 users, and only $10 \%$ were mentioned by more than 11 users. By checking the popularity distributions, the contact and friend networks followed a power-law $(\gamma=2.17$ and $\gamma=2.64)$. 62 students were not mentioned as a contact by any others, while 33 were not mention prior collaborations, and 33 not mentioned as friends. We calculated Gini coefficients of users' traits to check the distribution of users' skills among the case studies. We found that all traits were distributed equally among users: creativity $(\mathrm{M}=5.6, \mathrm{SD}=.96$, Gini=.09), leadership experience $(\mathrm{M}=3.87, \mathrm{SD}=.71$, $\mathrm{Gini}=.10)$, social skills $(\mathrm{M}=5.22, \mathrm{SD}=.87$, Gini $=.09)$, psychological collectivism $(\mathrm{M}=3.65, \mathrm{SD}=.51$, Gini=.08), and project skills $(\mathrm{M}=3.62$, $\mathrm{SD}=.64$, Gini=.10). Users' personality scores were normally distributed, and each trait's means were marginally above the middle of the scale (2.5): the lowest was openness score with $2.55(\mathrm{SD}=.46)$ and the highest was agreeableness with $3.04(\mathrm{SD}=.37)$.

\subsection{Search behavior}

In response to RQ1, we analyzed how users search for forming teams. $71.5 \%$ of the users made searches on the platform. 
$61.7 \%$ of the users used the search preferences to find others and $16.8 \%$ directly specified names to find others. Users made 1,138 queries in total. The mean user performed 3.48 queries $(\mathrm{SD}=7.00)$, where $44.3 \%$ of these users made between 2 and 5 queries. The mean query used $9.61(\mathrm{SD}=4.80)$ search preferences, where $54.7 \%$ of the queries used between 5 to 14 attributes.

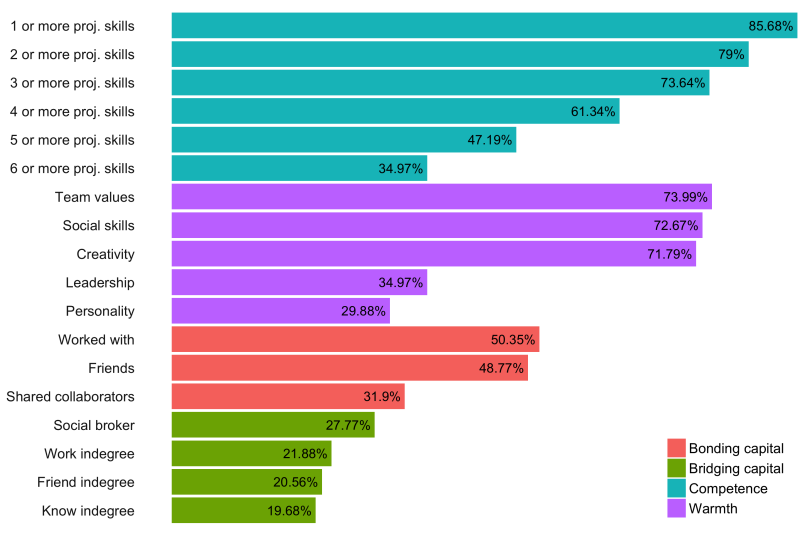

Figure 4: Search Preferences in Users' Search Queries

Figure 4 shows the most used search preferences across all users. Users preferred competence and warmth over bonding capital and bridging capital when they searched for potential teammates. Results suggest that users valued teammate characteristics on pairs with project skills. Users searched for at least one skill in $85.7 \%$ of the queries. Team values $(74.0 \%)$, social skills $(72.7 \%)$, and creativity $(71.8 \%)$ were frequently searched by users. Users also searched for past collaborators (50.4\%), friendship (48.8\%), and shared collaborators $(31.9 \%)$ over people's bridging capital.

We examined whether users' prior collaborations affected their use of social (bridging and bonding) capital search preferences. We found that users without any prior collaborations used bridging capital search preferences more times than users with prior collaborations: $64.9 \%$ versus $43.2 \%$ of the time in their queries. These results suggest that the search of brokers and popular users was a real alternative for those who were not well connected with others in these classes. Graduate and undergraduate students differed significantly in their bonding capital search behavior: undergraduates relied on friendship networks, whereas graduate students relied on work networks.

\subsection{Invitation behavior}

In response to RQ2, we examined factors that influenced their invitation behavior (who they decided to invite to teamup with them). Across all case studies, 282 users (53.2\% of the sample) extended a total of 1,066 invitations. Users sent an average of 3.78 invitations $(\mathrm{SD}=3.29)$. Table 2 reports the factors influencing the sending of invitations during each of the three stages. These are described in the following sections.

4.3.1 Initiating a team. While initiating a team, individuals were more likely to extend invitations to those they knew $(\beta=.04, p<.001)$, had previously collaborated with $(\beta=.08$, $p<.001)$, or with whom they were friends $(\beta=.1, p<.001)$. Senders who scored high on the trait of psychological collectivism were more likely to send an invite $(\beta=.005, p<.01)$. Recipients who rated themselves highly as leaders were more likely to receive an invite $(\beta=.006, p<.01)$. In addition, senders who rated themselves highly on project skills were more likely to send an invite $(\beta=.01, p<.05)$. Interestingly, users who reported a high number of friends $(\beta=-.02, p<.001)$ or collaborators $(\beta=-.02, p<.001)$ were less likely to send an invite. Users who others reported collaborating with were also less likely to send an invite $(\beta=-.01, p<.001)$.

4.3.2 Growing a team. At the second, growing a team stage, prior collaborations and existing social connections continued to positively influence whether an invite was sent: being a contact $(\beta=.04, p<.001)$, prior collaborator $(\beta=.08, p<.001)$, and being friends with the individual $(\beta=.03, p<.05)$. Unlike the initiating team stage, users with a lot of friends no longer less likely to extend invitations but those with a higher number of reported contacts $(\beta=-.01, p<.001)$ or reported prior collaborations $(\beta=-.01, p<.001)$ were less likely to send an invite.

4.3.3 Finalizing a team. Once again, bonding capital proved to be impactful in users' choices: being a prior collaborator $(\beta=.05, p<.001)$ or friends $(\beta=.06, p<.001)$ were positively significant. In this finalizing stage, however having higher bringing capital resulted in a lower likelihood of acceptance: users frequently reported as collaborators by others were less likely to receive an invitation $(\beta=-.02, p<.001)$. Females were more likely to receive an invitation $(\beta=.001, p<.05)$ as well as creative users $(\beta=.009, p<.01)$. Senders who scored high on the psychological collectivism trait were more likely to send an invite $(\beta=.007, p<.05)$. Finally, users reporting high leadership experience were less likely to receive an invite $(\beta=-.007, p<.05)$.

\subsection{Responding behavior}

Next, in response to RQ3, we analyzed the factors influencing users' distribution of received invitations. We removed from this analysis invitations for which they were no responses. 407 users $(76.8 \%$ of the sample) received at least one invitation. The rest had to wait until the end of the team assembly phases when instructor of the course assigned them 
Table 2: Sending Behavior HLM D.V. = Likelihood of sending an invitation

\begin{tabular}{|c|c|c|c|}
\hline & 1. Initiating a team & 2. Growing a team & 3. Finalizing a team \\
\hline $\begin{array}{l}\text { Fixed Effects } \\
\text { Competence }\end{array}$ & $\beta($ S.E. $)$ & $\beta$ (S.E.) & $\beta(S . E)$. \\
\hline $\begin{array}{l}\text { [S] Project skills sum } \\
\text { Warmth }\end{array}$ & $.018(.008)$ & - & - \\
\hline [S] Psych. Collectivism & $.006(.001)$ & - & $.007(.003)$ \\
\hline$[\mathrm{R}]$ Creativity & - & - & $.009(.003)$ \\
\hline $\begin{array}{l}{[\mathrm{R}] \text { Leadership }} \\
\text { Bonding capital }\end{array}$ & $.007(.002)$ & - & $-.007(.003)$ \\
\hline Contacts & $.04(.009)$ & $.04(.009)$ & - \\
\hline Collaborators & $.08(.007)$ & $.08(.007)$ & $.05(.013)$ \\
\hline Friends & $.13(.009)$ & $.03(.008)$ & $.06(.012)$ \\
\hline Bridging capital & & & \\
\hline [S] Contact activity & - & $-.01(.002)$ & - \\
\hline [S] Friendship activity & $-.02(.003)$ & - & - \\
\hline [S] Collab. Popularity & $-.01(.004)$ & - & - \\
\hline [S] Collab. activity & $-.02(.003)$ & $-.02(.004)$ & - \\
\hline [R] Collab. popularity & - & - & $-.024(.005)$ \\
\hline Demographics & & & \\
\hline [R] Gender (Female) & - & - & $.01(.005)$ \\
\hline Random Effects & $\sigma^{2}$ & $\sigma^{2}$ & $\sigma^{2}$ \\
\hline Project (Intercept) & .0003 & .0001 & .0002 \\
\hline Residual & .03 & .02 & .027 \\
\hline REML & $-5,126.9$ & $-9,303.8$ & $-2,801$ \\
\hline N. of Observations & 14,305 & 11,156 & 4,170 \\
\hline
\end{tabular}

in other teams. Table 3 reports the factors influencing the responses to invitations during each of the three stages. These are described in the following sections.

4.4.1 Initializing a team. When initializing a team, users were more likely to accept the first invitation that they received $(\beta=.22, p<.05)$, and less likely to accept an invitation if they had many other pending invitations to choose among ( $\beta=-.06, p<.05)$. Users were less likely to accept (or conversely, more likely to decline) invitations from individuals who scored high on the extraversion trait $(\beta=-.08, p<.05)$. Previous social connections were also significant in impacting decision making in the early stage of team formation: users were more likely to accept invitations from users who have collaborated with many people in the past $(\beta=.21, p<.01)$, but were more likely to decline invitations from users who knew many people $(\beta=-.17, p<.01)$. Users were also more likely to decline invitations if many others cited them as friends $(\beta=-.24, p<.05)$. Interestingly, competence had a negative effect: users were more likely to decline invitations from senders who reported possessing a large number of the skills required for the project.

4.4.2 Growing a team. During the growing a team stage, the users were more likely to accept an invitation from somebody who they already knew $(\beta=.19, p<.01)$, but curiously they were less likely to accept an invitation from somebody with whom they had previously collaborated $(\beta=-.12, p<.01)$. Users were more likely to accept invitation if they reported collaborating with many in the past $(\beta=.13, p<.05)$ or if others reported collaborating with them $(\beta=.10, p<.01)$.
Table 3: Accepting Behavior HLM

D.V. = Likelihood of accepting an invitation

\begin{tabular}{|c|c|c|c|}
\hline & 1. Initiating a team & 2. Growing a team & 3. Finalizing a team \\
\hline $\begin{array}{l}\text { Fixed Effects } \\
\text { Competence }\end{array}$ & $\beta($ S.E. $)$ & $\beta($ S.E. $)$ & $\beta($ S.E. $)$ \\
\hline $\begin{array}{l}\text { [S] Project skills sum } \\
\text { Warmth }\end{array}$ & $-.39(.18)$ & - & - \\
\hline [S] Social skills & - & - & $.14(.06)$ \\
\hline [S] Extraversion & $-.08(.04)$ & - & $-.08(.04)$ \\
\hline [S] Agreeableness & - & - & $-.09(.04)$ \\
\hline [S] Openness & - & - & $.09(.04)$ \\
\hline \multicolumn{4}{|l|}{ Bonding capital } \\
\hline Contacts & - & $.19(.06)$ & - \\
\hline Collaborators & - & $-.12(.06)$ & - \\
\hline \multicolumn{4}{|l|}{ Bridging capital } \\
\hline [S] Contact Activity & $-.17(.05)$ & - & - \\
\hline [S] Collab. Activity & $.21(.08)$ & $.11(.06)$ & - \\
\hline [S] Friend. Activity & - & - & $.13(.05)$ \\
\hline [R] Collab. Popularity & - & $.13(.06)$ & - \\
\hline [R] Friend. Popularity & $-.24(.11)$ & - & $.19(.08)$ \\
\hline \multicolumn{4}{|l|}{ Timing } \\
\hline [S] Has a team & - & - & $-.33(.17)$ \\
\hline [S] 1st invitation sent & $.22(.09)$ & - & - \\
\hline [R] Pending invitations & $-.06(.029)$ & $-.06(.01)$ & - \\
\hline Random Effects & $\sigma^{2}$ & $\sigma^{2}$ & $\sigma^{2}$ \\
\hline Project (Intercept) & .000 & .015 & .008 \\
\hline$\underline{\text { Residual }}$ & .15 & .13 & .07 \\
\hline REML & 346.6 & 581.7 & 187.3 \\
\hline N. of Observations & 189 & 430 & 107 \\
\hline
\end{tabular}

4.4.3 Finalizing a team. In the finalizing team stage, users were more likely to decline an invitation from a user who was already on a team $(\beta=-.33, p<.05)$. Users were more likely to accept invites from senders with higher social skills $(\beta=.13$, $p<.05)$ and those scoring higher on the openness trait $(\beta=.09$, $p<.05)$. On the other hand, users were more likely to decline invites from users scored high on the extraversion $(\beta=-.08$, $p<.05)$ and agreeableness $(\beta=-.09, p<.05)$ traits. Prior social connections were also important: users were more likely to accept invitations from those who were cited as friends by many $(\beta=.19, p<.05)$, and those who reported having many friends $(\beta=.13, p<.05)$.

\subsection{Team composition}

Finally, in response to RQ4, we examined how individuals' search, invitation, and response behaviors aggregated to emergent outcomes on team composition. In total, users formed 91 teams: $93.4 \%$ were self-assembled completely by users, 5.5\% required the intervention of the instructor (adding one or more members to the team), and $1.1 \%$ were assembled manually by the instructor.

Many teams were formed based, at least in part, on existing social connections. In $64.7 \%$ of teams, each user knew at least one other person in the team, in $36.5 \%$ of teams each user had previously collaborated at least one other team member, and in $48.2 \%$ of teams, each person was a friend with at least one team member. That said, $3.5 \%$ of teams were formed where nobody in knew each other, $12.9 \%$ were formed where 


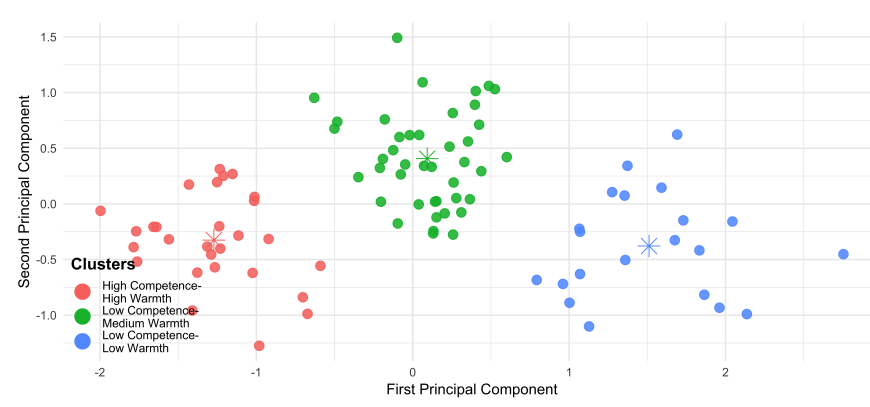

(a) Clusters based on Human Capital

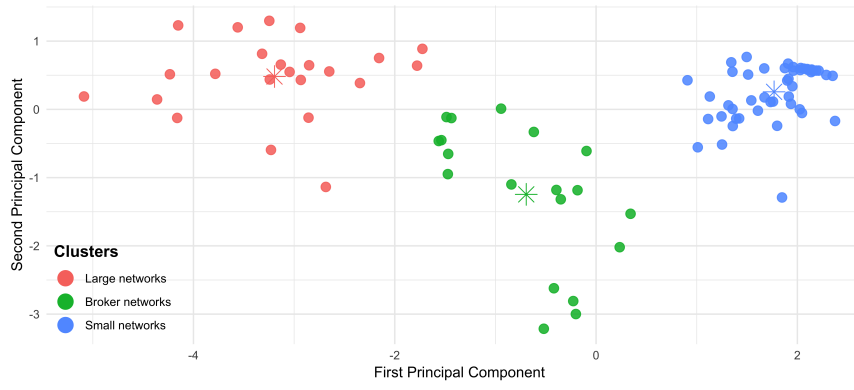

(b) Clusters based on Social Capital

Figure 5: Clusters detected according to the 91 assembled teams

nobody had collaborated with one another, and $9.4 \%$ were formed where nobody was friends with one another. To assess the distribution of human capital and social capital we clustered teams based on the users' responses to competence and warmth attributes as well as their social connections in the initial survey. We discuss these results next.

4.5.1 Human capital. We found that the teams belong to one of 3 clusters based on users' responses to competence and warmth attributes (Figure 5a). The first cluster, compromising $32 \%$ of the teams, were composed of members who were on average high on competence and warmth. The second group, compromising $44 \%$ of the teams, were composed who were average on warmth skills but below average on competence. Finally, the third cluster compromising $25 \%$ of the teams, were composed of members who were high on competence but low on warmth.

4.5.2 Social capital. We found that teams belong to one of three clusters (Figure 5b) based on their bridging capital attributes (i.e., popularity, activity, brokerage, and closeness). The first cluster, compromising $31 \%$ of the teams, teams were composed of members with high popularity (indegree), activity (outdegree), and closeness scores that were far above the average across all their social networks (i.e., contact, collaboration, friends). The second cluster, compromising $20 \%$ of the teams, teams were composed of members who had averages scores on popularity, activity, and closeness, but high scores on betweenness. These teams composed of members who, despite having modest sized networks, were especially adroit brokers. Finally, the third cluster, compromising $49 \%$ of the teams, were composed of users with below average bridging capital across all networks.

\section{DISCUSSION}

In this study, we analyzed users' behaviors on an online team formation system to search for and choose teammates. During the teammate search stage, users' queries included mostly competence and warmth attributes (RQ1): $86 \%$ of the queries included at least one project skill and $74 \%$ of them asked for members who valued teamwork. Regardless bridging and bonding capital were used in less than $50 \%$ of the queries, we found users' bridging capital and bonding capital were the most important factors for choosing a teammate.

Users' initial searches for competent and warm individuals were not translated to their final teammate selections. Despite the high importance of competence and warmth during the search stage, bonding capital was ultimately determinant in inviting others (RQ2). Even though the system provided multiple search choices sorted by expertise and social skills, users were more likely to invite someone with who they were more familiar. Less-connected users took advantage of using bridging capital search preferences; they searched for "social network brokers" and popular individuals more than highly-connected users. In terms of sending invitations, prior connections were dominant factors across all three team formation stages (i.e., initiating, growing, and finalizing), while some users' traits were relevant at the beginning (e.g., leadership experience) and others at the end (e.g., creativity and gender).

Users' decisions to accept or decline invitations relied on bonding capital and bridging capital: prior collaborations and popular users were more likely to be accepted, while neither competence nor warmth were significant factors across all three team formation stages of initiating, growing, and finalizing (RQ3). One explanation may be the lack of information provided to the invitee about the invitations' sender and, if any, about others on the sender's team. Although recipients were able to see senders' profiles on the platform, only a minority of recipients opened the profiles of the users who sent them invitations $(<10 \%)$. This shows an asymmetry with the senders, who had more information about the person they were inviting based on specific preferences they used to search for others. In addition to social capital, the need for a teammate also explained the acceptance of several of the invitations. Users were more likely to accept an invitation when they were looking for their first teammate, and when 
they only had a few options to choose from. Users who were alone (not in a team) or in a partial team with just a few others were more likely to accept invitations from a larger partial team. They relied mostly on the (smaller) size of their current team, rather than focusing on the potential senders' skills or expertise.

Finally, we found that users' search, invite, and response behaviors aggregated perniciously to create emergent teams that were segregated by users' human capital and social capital (RQ4): while most of the expertise and warm skills were concentrated in a small number of teams, a considerable number of teams were formed by novice users or less sociable individuals [17]. Similarly, the most connected users were concentrated in a small number of teams, and the majority of the teams had members with few social connections.

\subsection{Augmenting team formation processes}

In this study, we designed an experience that promoted users' agency to select their teammates and the outcomes were not inconsistent with the literature on team formation: social connections are fundamental for teammate selection [37]. Considering this dependency on prior social connections, we question how future team formation systems can enable users to consider other factors beyond their prior social connections, such as the balance and diversity of their skills or backgrounds [66].

Computational augmentation can facilitate users' team formation processes when they have agency to self-assemble $[1,24,72]$ : systems can learn from users' traits and social networks to provide feedback in their searches and choices, detecting the strengths and weaknesses of each user [87], and reduce the bias produced by the use of competence and warmth at the search phase, as well as the bias produced by bonding and bridging capital in the invitation and response phases. Future systems can provide users with the option to simulate the formation of their teams [3]. For example, the system might ask users to provide their ideal teammates or needed skills. Users can visualize and plan balanced and skilled teams, in order to understand what are the missing skills or resources needed in their groups. This simulation approach would allow the system to understand how each user would form their own team if they were able to dictate their circumstances.

Finally, systems could interact with the users as social agents in these search and choice processes [27, 59]. Since users' interactions were asynchronous, the system can become an agent who interacts with each user and become a social broker. Systems can be also part of these negotiation stages between users, offering suggestions or making new connections in order to increase the likelihood of diverse teams.

\subsection{Emergence of segregated teams}

A key, and disturbing takeaway, from this study is that platforms designed to flatten the playing field for team formation can unintentionally enable greater segregation. The concentration of human capital and social capital in a small number of teams reveals one of the main issues with allowing users' agency for choosing teammates. Users' choices led to the social exclusion of certain users, where many teams were filling missing members just to complete the team size requirement. Additionally, those who received many invitations had more potential teammates to choose from, and therefore, greater influence in the final team composition, creating an imbalance in the equation of team formation among all users [34]. The design of team formation systems can hinder the emergence of functional diversity $[11,20]$, which brings different domains of knowledge and experiences in a single team, as well as the teams' connectivity $[57,72]$, which provides access to different networks and resources [51]. Future systems should include mechanisms that enable the formation of teams with balanced skills and social connections [78]. For instance, systems can offer potential teammates diversity metrics in terms of skills, traits, and connectivity.

The design of team assembly platforms have the inevitable trade-off: on one hand systems can form teams by optimizing users' expertise and qualities but without considering users' preferences; on the other, systems can grant users full agency for choosing their teammates but without considering the macro-level outcomes. The extent to which users can exercise personal agency challenges the formation of functionally diverse teams. HCI researches must consider how this team formation pipeline aims to maximize the probability of assembling functional teams by allowing users to search and invite others. Future systems can complement both approaches by offering dynamic interfaces: for example, the system might consider reconfiguring teams as the team formation process advances [87], providing enhanced alternatives to its users [25], and involving instructors or managers to be part of the team formation processes [42].

\subsection{Limitations and future work}

One important limitation of this study is the participation of only students in the U.S., who are may not be representative of other demographic groups. More case studies in other environments would contribute to assess the generalizability of team assembly factors identified in this study. Second, users' self-reported skills may not be realistic: in future, peer-evaluations should confirm others' expertise. Third, we acknowledge that our system configuration and design affected users' searches and team formation processes. The system likely induced certain search preferences and decisions, precluding alternatives that in other contexts they 
would have considered. Fourth, we did not control students' interactions during the lectures and outside of them: some teams may have formed because students agreed to do so offline, but that was not possible to measure. Fifth, we cannot infer cause-and-effect relationships among users' traits, their final teammates' choices, and the use of team search systems. Future experimental designs should test our RQs to infer causality. Finally, we did not measure teams' performance after they were assembled. There are indeed valuable questions to be asked surrounding how people adjust their assembly strategies based on past team performance. Future research should consider using ratings of project outcomes, rubrics, standardized non-graded tests, exit surveys, and other metrics to link team formation processes with team performance.

\section{CONCLUSION}

This study reveals the high relevance of competence and warmth as factors that drive users' searches. However, bonding capital was the most important factor in choosing a teammate. Users' behaviors led to segregated teams. We gained insight into people's underlying decision rules and how they shift according to their team composition. We envision new designs for team formation systems that augment users' capacity for assembling more functional, cohesive, and connected teams that take into consideration users' skills, traits, and social connections.

\section{ACKNOWLEDGMENTS}

This work is supported by the Northwestern University Office of Provost, NSF IIS-1514427, NIH R01GM112938-01, and the Army Research Lab W911NF-09-2-0053.

The authors would like to thank the Northwestern SONIC Lab members, Silvia Andreoli, Denis Parra, Eduardo Graells, Alexa Harris, Eleanor Burgess, Nicole Lipschultz, and Darren Gergle for their feedback and conversations. The authors would also like to thank the anonymous referees for their valuable comments and helpful suggestions. We also thank Anup Sawant and Xiang Li for the deployment of the team formation tool.

\section{REFERENCES}

[1] Mark S. Ackerman. 2000. The intellectual challenge of CSCW: the gap between social requirements and technical feasibility. HumanComputer Interaction 15, 2-3 (2000), 179-203.

[2] Rakesh Agrawal, Behzad Golshan, and Evimaria Terzi. 2014. Grouping Students in Educational Settings. In Proceedings of the 20th ACM SIGKDD International Conference on Knowledge Discovery and Data Mining (KDD '14). ACM, New York, NY, USA, 1017-1026. https: //doi.org/10.1145/2623330.2623748

[3] Oznur Alkan, Elizabeth M. Daly, and Inge Vejsbjerg. 2018. Opportunity Team Builder for Sales Teams. In 23rd International Conference on Intelligent User Interfaces (IUI '18). ACM, New York, NY, USA, 251-261. https://doi.org/10.1145/3172944.3172968
[4] Iheb Ben Amor, Salima Benbernou, Mourad Ouziri, Zaki Malik, and Brahim Medjahed. 2016. Discovering Best Teams for Data Leak-Aware Crowdsourcing in Social Networks. ACM Trans. Web 10, 1, Article 2 (Feb. 2016), 27 pages. https://doi.org/10.1145/2814573

[5] Aris Anagnostopoulos, Luca Becchetti, Carlos Castillo, Aristides Gionis, and Stefano Leonardi. 2010. Power in Unity: Forming Teams in Large-scale Community Systems. In Proceedings of the 19th ACM International Conference on Information and Knowledge Management (CIKM '10). ACM, New York, NY, USA, 599-608. https://doi.org/10. $1145 / 1871437.1871515$

[6] Deborah G. Ancona and David F. Caldwell. 1992. Bridging the Boundary: External Activity and Performance in Organizational Teams. Administrative Science Quarterly 37, 4 (1992), 634-665. http://www.jstor. org/stable/2393475

[7] Pierre Balthazard, Richard E. Potter, and John Warren. 2004. Expertise, Extraversion and Group Interaction Styles As Performance Indicators in Virtual Teams: How Do Perceptions of IT's Performance Get Formed? SIGMIS Database 35, 1 (Feb. 2004), 41-64. https: //doi.org/10.1145/968464.968469

[8] Gary S Becker. 1994. Human capital revisited. In Human Capital: A Theoretical and Empirical Analysis with Special Reference to Education (3rd Edition). The University of Chicago Press, 15-28.

[9] Suzanne T Bell. 2007. Deep-level composition variables as predictors of team performance: a meta-analysis. Journal of applied psychology 92, 3 (2007), 595.

[10] Anthony S Bryk and Stephen W Raudenbush. 1992. Hierarchical linear models for social and behavioral research: Applications and data analysis methods.

[11] J. Stuart Bunderson and Kathleen M. Sutcliffe. 2002. Comparing Alternative Conceptualizations of Functional Diversity in Management Teams: Process and Performance Effects. Academy of Management fournal 45, 5 (2002), 875-893. https://doi.org/10.5465/3069319 arXiv:https://doi.org/10.5465/3069319

[12] Iryna Bursuk, Andreas Mladenow, Niina Maarit Novak, and Christine Strauss. 2016. Online Cofounder Search in Tech Startups. In Proceedings of the 18th International Conference on Information Integration and Webbased Applications and Services (iiWAS '16). ACM, New York, NY, USA, 482-488. https://doi.org/10.1145/3011141.3011221

[13] Ronald S. Burt. 1997. The Contingent Value of Social Capital. Administrative Science Quarterly 42, 2 (1997), 339-365. http://www.jstor.org/ stable/2393923

[14] Ronald S Burt et al. 2005. Brokerage and closure: An introduction to social capital. Oxford University Press.

[15] Cristina Cabanillas, Manuel Resinas, Jan Mendling, and Antonio RuizCortés. 2015. Automated Team Selection and Compliance Checking in Business Processes. In Proceedings of the 2015 International Conference on Software and System Process (ICSSP 2015). ACM, New York, NY, USA, 42-51. https://doi.org/10.1145/2785592.2785613

[16] Albert V. Carron and Lawrence R. Brawley. 2000. Cohesion: Conceptual and Measurement Issues. Small Group Research 31, 1 (2000), 89-106. https://doi.org/10.1177/104649640003100105 arXiv:https://doi.org/10.1177/104649640003100105

[17] Tiziana Casciaro and Miguel Sousa Lobo. 2005. Competent jerks, lovable fools, and the formation of social networks. Harvard Business Review 83, 6 (2005), 92-99.

[18] CBInsights. 2018. The Top 20 Reasons Startups Fail. https://www. cbinsights.com/research/startup-failure-reasons-top/

[19] Jilin Chen, Werner Geyer, Casey Dugan, Michael Muller, and Ido Guy. 2009. Make New Friends, but Keep the Old: Recommending People on Social Networking Sites. In Proceedings of the SIGCHI Conference on Human Factors in Computing Systems (CHI '09). ACM, New York, NY, USA, 201-210. https://doi.org/10.1145/1518701.1518735 
[20] Siu Yin Cheung, Yaping Gong, Mo Wang, Le (Betty) Zhou, and Junqi Shi. 2016. When and how does functional diversity influence team innovation? The mediating role of knowledge sharing and the moderation role of affect-based trust in a team. Human Relations 69, 7 (2016), 1507-1531. https://doi.org/10.1177/0018726715615684 arXiv:https://doi.org/10.1177/0018726715615684

[21] Alvin Chin, Bin Xu, and Hao Wang. 2013. Who Should I Add As a "Friend"?: A Study of Friend Recommendations Using Proximity and Homophily. In Proceedings of the 4th International Workshop on Modeling Social Media (MSM '13). ACM, New York, NY, USA, Article 7, 7 pages. https://doi.org/10.1145/2463656.2463663

[22] James S. Coleman. 1988. Social Capital in the Creation of Human Capital. Amer. F. Sociology 94 (1988), S95-S120. https://doi.org/10. 1086/228943 arXiv:https://doi.org/10.1086/228943

[23] Noshir Contractor. 2013. Some assembly required: leveraging Web science to understand and enable team assembly. Philosophical Transactions of the Royal Society A: Mathematical, Physical and Engineering Sciences 371, 1987 (2013), 20120385. https://doi.org/10.1098/rsta.2012.0385 arXiv:https://royalsocietypublishing.org/doi/pdf/10.1098/rsta.2012.0385

[24] David Coyle, James Moore, Per Ola Kristensson, Paul Fletcher, and Alan Blackwell. 2012. I Did That! Measuring Users' Experience of Agency in Their Own Actions. In Proceedings of the SIGCHI Conference on Human Factors in Computing Systems (CHI '12). ACM, New York, NY, USA, 2025-2034. https://doi.org/10.1145/2207676.2208350

[25] Anwitaman Datta, Jackson Tan Teck Yong, and Anthony Ventresque. 2011. T-RecS: Team Recommendation System Through Expertise and Cohesiveness. In Proceedings of the 20th International Conference Companion on World Wide Web (WWW'11). ACM, New York, NY, USA, 201-204. https://doi.org/10.1145/1963192.1963289

[26] M Brent Donnellan, Frederick L Oswald, Brendan M Baird, and Richard E Lucas. 2006. The mini-IPIP scales: tiny-yet-effective measures of the Big Five factors of personality. Psychological assessment 18, 2 (2006), 192.

[27] Emilio Ferrara, Onur Varol, Clayton Davis, Filippo Menczer, and Alessandro Flammini. 2016. The Rise of Social Bots. Commun. ACM 59, 7 (June 2016), 96-104. https://doi.org/10.1145/2818717

[28] Gerald R. Ferris, Darren C. Treadway, Robert W. Kolodinsky, Wayne A. Hochwarter, Charles J. Kacmar, Ceasar Douglas, and Dwight D. Frink. 2005. Development and Validation of the Political Skill Inventory. fournal of Management 31, 1 (2005), 126-152. https://doi.org/10.1177/ 0149206304271386 arXiv:https://doi.org/10.1177/0149206304271386

[29] Susan T. Fiske, Amy J.C. Cuddy, and Peter Glick. 2007. Universal dimensions of social cognition: warmth and competence. Trends in Cognitive Sciences 11, 2 (2007), 77 - 83. https://doi.org/10.1016/j.tics. 2006.11.005

[30] Ge Gao, Pamela Hinds, and Chen Zhao. 2013. Closure vs. Structural Holes: How Social Network Information and Culture Affect Choice of Collaborators. In Proceedings of the 2013 Conference on Computer Supported Cooperative Work (CSCW'13). ACM, New York, NY, USA, 5-18. https://doi.org/10.1145/2441776.2441781

[31] Gary Garrison, Robin L. Wakefield, Xiaobo Xu, and Sang Hyun 'Kim. 2010. Globally Distributed Teams: The Effect of Diversity on Trust, Cohesion and Individual Performance. SIGMIS Database 41, 3 (Aug. 2010), 27-48. https://doi.org/10.1145/1851175.1851178

[32] Lucy L. Gilson, M. Travis Maynard, Nicole C. Jones Young, Matti Vartiainen, and Marko Hakonen. 2015. Virtual Teams Research: 10 Years, 10 Themes, and 10 Opportunities. Fournal of Management 41, 5 (2015), 1313-1337. https://doi.org/10.1177/0149206314559946 arXiv:https://doi.org/10.1177/0149206314559946

[33] Mark S. Granovetter. 1977. The Strength of Weak Ties11This paper originated in discussions with Harrison White, to whom I am indebted for many suggestions and ideas. Earlier drafts were read by Ivan Chase, James Davis, William Michelson, Nancy Lee, Peter Rossi, Charles Tilly, and an anonymous referee; their criticisms resulted in significant improvements. In Social Networks, Samuel Leinhardt (Ed.). Academic Press, 347 - 367. https://doi.org/10.1016/B978-0-12-442450-0.50025-0

[34] Lindred L Greer. 2014. Power in teams: Effects of team power structures on team conflict and team outcomes. Handbook of conflict management research (2014), 93-108.

[35] Roger Guimerà, Brian Uzzi, Jarrett Spiro, and Luís A. Nunes Amaral. 2005. Team Assembly Mechanisms Determine Collaboration Network Structure and Team Performance. Science 308, 5722 (2005), 697-702. https://doi.org/10.1126/science.1106340 arXiv:http://science.sciencemag.org/content/308/5722/697.full.pdf

[36] Ido Guy, Sigalit Ur, Inbal Ronen, Sara Weber, and Tolga Oral. 2012. Best Faces Forward: A Large-scale Study of People Search in the Enterprise. In Proceedings of the SIGCHI Conference on Human Factors in Computing Systems (CHI '12). ACM, New York, NY, USA, 1775-1784. https://doi. org $/ 10.1145 / 2207676.2208310$

[37] Pamela J Hinds, Kathleen M Carley, David Krackhardt, and Doug Wholey. 2000. Choosing Work Group Members: Balancing Similarity, Competence, and Familiarity. Organizational Behavior and Human Decision Processes 81, 2 (2000), 226 - 251. https://doi.org/10.1006/obhd. 1999.2875

[38] Rashina Hoda, James Noble, and Stuart Marshall. 2011. The impact of inadequate customer collaboration on self-organizing Agile teams. Information and Software Technology 53, 5 (2011), 521 - 534. https: //doi.org/10.1016/j.infsof.2010.10.009 Special Section on Best Papers from XP2010.

[39] Albert Hupa, Krzysztof Rzadca, Adam Wierzbicki, and Anwitaman Datta. 2010. Interdisciplinary Matchmaking: Choosing Collaborators by Skill, Acquaintance and Trust. Springer London, London, 319-347. https://doi.org/10.1007/978-1-84882-229-0_12

[40] Farnaz Irannejad Bisafar, Aditya Ponnada, Ameneh Shamekhi, and Andrea G. Parker. 2017. A Sociotechnical Study of a Community-based Rewards Program: Insights on Building Social, Financial and Human Capital. Proc. ACM Hum.-Comput. Interact. 1, CSCW, Article 55 (Dec. 2017), 21 pages. https://doi.org/10.1145/3134690

[41] Christine L Jackson, Jason A Colquitt, Michael J Wesson, and Cindy P Zapata-Phelan. 2006. Psychological collectivism: A measurement validation and linkage to group member performance. Journal of Applied Psychology 91, 4 (2006), 884.

[42] Farnaz Jahanbakhsh, Wai-Tat Fu, Karrie Karahalios, Darko Marinov, and Brian Bailey. 2017. You Want Me to Work with Who?: Stakeholder Perceptions of Automated Team Formation in Project-based Courses. In Proceedings of the 2017 CHI Conference on Human Factors in Computing Systems (CHI '17). ACM, New York, NY, USA, 3201-3212. https://doi.org/10.1145/3025453.3026011

[43] Oskar Jarczyk, Błażej Gruszka, Szymon Jaroszewicz, Leszek Bukowski, and Adam Wierzbicki. 2014. GitHub Projects. Quality Analysis of Open-Source Software. Springer International Publishing, Cham, 80-94. https://doi.org/10.1007/978-3-319-13734-6_6

[44] Young Ji Kim, David Engel, Anita Williams Woolley, Jeffrey Yu-Ting Lin, Naomi McArthur, and Thomas W. Malone. 2017. What Makes a Strong Team?: Using Collective Intelligence to Predict Team Performance in League of Legends. In Proceedings of the 2017 ACM Conference on Computer Supported Cooperative Work and Social Computing (CSCW '17). ACM, New York, NY, USA, 2316-2329. https: //doi.org/10.1145/2998181.2998185

[45] Richard A Layton, Misty L Loughry, Matthew W Ohland, and George D Ricco. 2010. Design and Validation of a Web-Based System for Assigning Members to Teams Using Instructor-Specified Criteria. Advances in Engineering Education 2, 1 (2010), n1. 
[46] Michael Y. Lee and Amy C. Edmondson. 2017. Self-managing organizations: Exploring the limits of less-hierarchical organizing. Research in Organizational Behavior 37 (2017), 35 - 58. https://doi.org/10.1016/ j.riob.2017.10.002

[47] Soo Ling Lim, Daniele Quercia, and Anthony Finkelstein. 2010. StakeNet: Using Social Networks to Analyse the Stakeholders of Large-scale Software Projects. In Proceedings of the 32Nd ACM/IEEE International Conference on Software Engineering - Volume 1 (ICSE '10). ACM, New York, NY, USA, 295-304. https://doi.org/10.1145/1806799.1806844

[48] Nan Lin. 2017. Building a network theory of social capital. In Social capital. Routledge, 3-28.

[49] Alina Lungeanu, Dorothy R. Carter, Leslie A. DeChurch, and Noshir S. Contractor. 2018. How Team Interlock Ecosystems Shape the Assembly of Scientific Teams: A Hypergraph Approach. Communication Methods and Measures 12, 2-3 (2018), 174-198. https://doi.org/10.1080/19312458. 2018.1430756 arXiv:https://doi.org/10.1080/19312458.2018.1430756

[50] Ioanna Lykourentzou, Robert E. Kraut, and Steven P. Dow. 2017. Team Dating Leads to Better Online Ad Hoc Collaborations. In Proceedings of the 2017 ACM Conference on Computer Supported Cooperative Work and Social Computing (CSCW '17). ACM, New York, NY, USA, 2330-2343. https://doi.org/10.1145/2998181.2998322

[51] Elizabeth Mannix and Margaret A. Neale. 2005. What Differences Make a Difference?: The Promise and Reality of Diverse Teams in Organizations. Psychological Science in the Public Interest 6, 2 (2005), 31-55. https://doi.org/10.1111/j.1529-1006.2005. 00022.x arXiv:https://doi.org/10.1111/j.1529-1006.2005.00022.x PMID: 26158478.

[52] John Mathieu, M. Travis Maynard, Tammy Rapp, and Lucy Gilson. 2008. Team Effectiveness 1997-2007: A Review of Recent Advancements and a Glimpse Into the Future. fournal of Management 34, 3 (2008), 410-476. https://doi.org/10.1177/0149206308316061 arXiv:https://doi.org/10.1177/0149206308316061

[53] John E. Mathieu, Scott I. Tannenbaum, Jamie S. Donsbach, and George M. Alliger. 2014. A Review and Integration of Team Composition Models: Moving Toward a Dynamic and Temporal Framework. fournal of Management 40, 1 (2014), 130-160. https://doi.org/10.1177/ 0149206313503014 arXiv:https://doi.org/10.1177/0149206313503014

[54] Peter R Monge, Peter S Contractor, and Noshir S Contractor. 2003. Theories of communication networks. Oxford University Press, USA.

[55] Michael Muller, Kate Ehrlich, Tara Matthews, Adam Perer, Inbal Ronen, and Ido Guy. 2012. Diversity Among Enterprise Online Communities: Collaborating, Teaming, and Innovating Through Social Media. In Proceedings of the SIGCHI Conference on Human Factors in Computing Systems (CHI '12). ACM, New York, NY, USA, 2815-2824. https://doi. org $/ 10.1145 / 2207676.2208685$

[56] Michael D. Mumford, Wayne A. Baughman, K. Victoria Threlfall, Charles E. Uhlman, and David P. Costanza. 1993. Personality, Adaptability, and Performance: Performance on WellDefined Problem Solving Tasks. Human Performance 6, 3 (1993), 241-285. https://doi.org/10.1207/s15327043hup0603_4 arXiv:https://doi.org/10.1207/s15327043hup0603_4

[57] Janine Nahapiet and Sumantra Ghoshal. 1998. Social Capital, Intellectual Capital, and the Organizational Advantage. The Academy of Management Review 23, 2 (1998), 242-266. http://www.jstor.org/ stable/259373

[58] Fernando Felix do Nascimento Junior, Allan Sales da Costa Melo, Igor Barbosa da Costa, and Leandro Balby Marinho. 2017. Profiling Successful Team Behaviors in League of Legends. In Proceedings of the 23rd Brazillian Symposium on Multimedia and the Web (WebMedia '17). ACM, New York, NY, USA, 261-268. https://doi.org/10.1145/3126858.3126886

[59] Clifford Nass and Youngme Moon. 2000. Machines and Mindlessness: Social Responses to Computers. Fournal of Social Issues
56, 1 (2000), 81-103. https://doi.org/10.1111/0022-4537.00153 arXiv:https://spssi.onlinelibrary.wiley.com/doi/pdf/10.1111/00224537.00153

[60] Catherine Neubauer, Joshua Woolley, Peter Khooshabeh, and Stefan Scherer. 2016. Getting to Know You: A Multimodal Investigation of Team Behavior and Resilience to Stress. In Proceedings of the 18th ACM International Conference on Multimodal Interaction (ICMI 2016). ACM, New York, NY, USA, 193-200. https://doi.org/10.1145/2993148.2993195

[61] Jacqueline Ng, Paul Leonardi, and Noshir Contractor. 2017. Teaming at the Limit: Enhancing Team Effectiveness with Enterprise Social Media Affordances. Academy of Management Proceedings 2017, 1 (2017), 13836. https://doi.org/10.5465/ambpp.2017.13 arXiv:https://doi.org/10.5465/ambpp.2017.13

[62] Hongseok Oh, Giuseppe Labianca, and Myung-Ho Chung. 2006. A Multilevel Model of Group Social Capital. Academy of Management Review 31, 3 (2006), 569-582. https://doi.org/10.5465/amr.2006.21318918 arXiv:https://doi.org/10.5465/amr.2006.21318918

[63] Paul Osterman. 1995. Skill, Training, and Work Organization in American Establishments. Industrial Relations: A fournal of Economy and Society 34, 2 (1995), 125-146. https://doi.org/10.1111/j.1468-232X.1995. tb00365.x arXiv:https://onlinelibrary.wiley.com/doi/pdf/10.1111/j.1468232X.1995.tb00365.x

[64] Daniele Quercia and Licia Capra. 2009. FriendSensing: Recommending Friends Using Mobile Phones. In Proceedings of the Third ACM Conference on Recommender Systems (RecSys '09). ACM, New York, NY, USA, 273-276. https://doi.org/10.1145/1639714.1639766

[65] Daniela Retelny, Sébastien Robaszkiewicz, Alexandra To, Walter S. Lasecki, Jay Patel, Negar Rahmati, Tulsee Doshi, Melissa Valentine, and Michael S. Bernstein. 2014. Expert Crowdsourcing with Flash Teams. In Proceedings of the 27th Annual ACM Symposium on User Interface Software and Technology (UIST '14). ACM, New York, NY, USA, 75-85. https://doi.org/10.1145/2642918.2647409

[66] Lionel Robert and Daniel M. Romero. 2015. Crowd Size, Diversity and Performance. In Proceedings of the 33rd Annual ACM Conference on Human Factors in Computing Systems (CHI '15). ACM, New York, NY, USA, 1379-1382. https://doi.org/10.1145/2702123.2702469

[67] Eduardo Salas, Rebecca Grossman, Ashley M. Hughes, and Chris W. Coultas. 2015. Measuring Team Cohesion: Observations from the Science. Human Factors 57, 3 (2015), 365-374. https://doi.org/10.1177/ 0018720815578267 arXiv:https://doi.org/10.1177/0018720815578267 PMID: 25875429 .

[68] Niloufar Salehi, Andrew McCabe, Melissa Valentine, and Michael Bernstein. 2017. Huddler: Convening Stable and Familiar Crowd Teams Despite Unpredictable Availability. In Proceedings of the 2017 ACM Conference on Computer Supported Cooperative Work and Social Computing (CSCW '17). ACM, New York, NY, USA, 1700-1713. https://doi.org/10.1145/2998181.2998300

[69] Ashay Saxena and Johanna Burmann. 2014. Factors Affecting Team Performance in Globally Distributed Setting. In Proceedings of the 52Nd ACM Conference on Computers and People Research (SIGSIM-CPR '14). ACM, New York, NY, USA, 25-33. https://doi.org/10.1145/2599990. 2599995

[70] Aaron Schecter, Andrew Pilny, Alice Leung, Marshall Scott Poole, and Noshir Contractor. 2018. Step by step: Capturing the dynamics of work team process through relational event sequences. Fournal of Organizational Behavior 39, 9 (2018), 1163-1181. https://doi.org/10.1002/job. 2247 arXiv:https://onlinelibrary.wiley.com/doi/pdf/10.1002/job.2247

[71] Jan B. Schmutz, Zhike Lei, Walter J. Eppich, and Tanja Manser. [n. d.]. Reflection in the heat of the moment: The role of in-action team reflexivity in health care emergency teams. Journal of Organizational Behavior 39, 6 ([n. d.]), 749-765. https://doi.org/10.1002/job.2299 arXiv:https://onlinelibrary.wiley.com/doi/pdf/10.1002/job.2299 
[72] Matthew S. Smith. 2008. Social Capital in Online Communities. In Proceedings of the $2 \mathrm{Nd}$ PhD Workshop on Information and Knowledge Management (PIKM '08). ACM, New York, NY, USA, 17-24. https: //doi.org/10.1145/1458550.1458554

[73] Howard Spoelstra, Peter van Rosmalen, Tilly Houtmans, and Peter Sloep. 2015. Team formation instruments to enhance learner interactions in open learning environments. Computers in Human Behavior 45 (2015), 11 - 20. https://doi.org/10.1016/j.chb.2014.11.038

[74] Pang-Ning Tan, Michael Steinbach, Anuj Karpatne, and Vipin Kumar. 2007. Introduction to Data Mining. Pearson Education. https://www.pearson.com/us/higher-education/program/ Tan-Introduction-to-Data-Mining-2nd-Edition/PGM214749.html

[75] Pamela Tierney and Steven M. Farmer. 2002. Creative Self-Efficacy: Its Potential Antecedents and Relationship to Creative Performance. Academy of Management fournal 45, 6 (2002), 1137-1148. https://doi org/10.5465/3069429 arXiv:https://doi.org/10.5465/3069429

[76] Erik H. Trainer, Arun Kalyanasundaram, Chalalai Chaihirunkarn, and James D. Herbsleb. 2016. How to Hackathon: Socio-technical Tradeoffs in Brief, Intensive Collocation. In Proceedings of the 19th ACM Conference on Computer-Supported Cooperative Work \& Social Computing (CSCW '16). ACM, New York, NY, USA, 1118-1130. https: //doi.org/10.1145/2818048.2819946

[77] Brian Uzzi, Satyam Mukherjee, Michael Stringer, and Ben Jones. 2013. Atypical Combinations and Scientific Impact. Science 342, 6157 (2013), 468-472. https://doi.org/10.1126/science.1240474 arXiv:http://science.sciencemag.org/content/342/6157/468.full.pdf

[78] Bogdan Vasilescu, Daryl Posnett, Baishakhi Ray, Mark G.J. van den Brand, Alexander Serebrenik, Premkumar Devanbu, and Vladimir Filkov. 2015. Gender and Tenure Diversity in GitHub Teams. In Proceedings of the 33rd Annual ACM Conference on Human Factors in Computing Systems (CHI '15). ACM, New York, NY, USA, 3789-3798. https://doi.org/10.1145/2702123.2702549

[79] Stanley Wasserman and Katherine Faust. 1994. Social Network Analysis: Methods and Applications. Cambridge University Press. https://doi. org/10.1017/CBO9780511815478

[80] Wouter Weerkamp, Richard Berendsen, Bogomil Kovachev, Edgar Meij, Krisztian Balog, and Maarten de Rijke. 2011. People Searching for People: Analysis of a People Search Engine Log. In Proceedings of the 34th International ACM SIGIR Conference on Research and Development in Information Retrieval (SIGIR '11). ACM, New York, NY, USA, 45-54. https://doi.org/10.1145/2009916.2009927

[81] Miaomiao Wen, Keith Maki, Steven Dow, James D. Herbsleb, and Carolyn Rose. 2017. Supporting Virtual Team Formation Through Community-Wide Deliberation. Proc. ACM Hum.-Comput. Interact.
1, CSCW, Article 109 (Dec. 2017), 19 pages. https://doi.org/10.1145/ 3134744

[82] Anita Williams Woolley, Christopher F. Chabris, Alex Pentland, Nada Hashmi, and Thomas W. Malone. 2010. Evidence for a Collective Intelligence Factor in the Performance of Human Groups. Science 330, 6004 (2010), 686-688. https://doi.org/10.1126/science.1193147 arXiv:http://science.sciencemag.org/content/330/6004/686.full.pdf

[83] Y. Connie Yuan and Geri Gay. 2006. Homophily of Network Ties and Bonding and Bridging Social Capital in Computer-Mediated Distributed Teams. Fournal of Computer-Mediated Communication 11, 4 (2006), 1062-1084. https://doi.org/10.1111/j.1083-6101.2006.00308.x

[84] Stephen J. Zaccaro. 1991. Nonequivalent Associations Between Forms of Cohesiveness and Group-Related Outcomes: Evidence for Multidimensionality. The fournal of Social Psychology 131, 3 (1991), 387-399. https://doi.org/10.1080/00224545.1991.9713865 arXiv:https://doi.org/10.1080/00224545.1991.9713865

[85] Jiawei Zhang, Yuanhua Lv, and Philip Yu. 2015. Enterprise Social Link Recommendation. In Proceedings of the 24th ACM International on Conference on Information and Knowledge Management (CIKM '15). ACM, New York, NY, USA, 841-850. https://doi.org/10.1145/2806416. 2806549

[86] Chen Zhao, Pamela Hinds, and Ge Gao. 2012. How and to Whom People Share: The Role of Culture in Self-disclosure in Online Communities. In Proceedings of the ACM 2012 Conference on Computer Supported Cooperative Work (CSCW'12). ACM, New York, NY, USA, 67-76. https: //doi.org/10.1145/2145204.2145219

[87] Sharon Zhou, Melissa Valentine, and Michael S. Bernstein. 2018. In Search of the Dream Team: Temporally Constrained Multi-Armed Bandits for Identifying Effective Team Structures. In Proceedings of the 2018 CHI Conference on Human Factors in Computing Systems (CHI '18). ACM, New York, NY, USA, Article 108, 13 pages. https://doi.org/10. $1145 / 3173574.3173682$

[88] Doug Zytko, Guo Freeman, Sukeshini A. Grandhi, Susan C. Herring, and Quentin (Gad) Jones. 2015. Enhancing Evaluation of Potential Dates Online Through Paired Collaborative Activities. In Proceedings of the 18th ACM Conference on Computer Supported Cooperative Work \&\#38; Social Computing (CSCW'15). ACM, New York, NY, USA, 18491859. https://doi.org/10.1145/2675133.2675184

[89] Doug Zytko, Jessa Lingel, Jeremy Birnholtz, Nicole B. Ellison, and Jeff Hancock. 2015. Online Dating As Pandora's Box: Methodological Issues for the CSCW Community. In Proceedings of the 18th ACM Conference Companion on Computer Supported Cooperative Work \&\#38; Social Computing (CSCW'15 Companion). ACM, New York, NY, USA, 131-134. https://doi.org/10.1145/2685553.2699335 